Leading Article

\title{
Effects of alcoholism on brain size
}

\author{
R.R. Jacobson \\ Department of Psychiatry, Jenner Wing, St. George's Hospital Medical School, Cranmer Terrace, London SW17 \\ $O R E, U K$.
}

The definition of alcoholism has long been marked by uncertainty and conflict, yet no better term exists to describe chronic and dependent overconsumption. Alcohol is drunk mostly for its pharmacological effects on the central nervous system (CNS), and when dependence sets in, consumption is increased because of tolerance and the need to avoid withdrawal symptoms. The effects on the CNS include direct intoxication, the consequences of withdrawal after tolerance, cerebral trauma related to intoxication, cerebro-vascular events, and the results of liver disease and secondary malnutrition.

The question of diffuse cerebral atrophy in alcoholics with attendant functional deficits has had a chequered history. ${ }^{1}$ Courville ${ }^{2}$ found widespread cortical atrophy in alcoholics at autopsy, and believed that alcoholism was the commonest cause of these changes in the 5th and 6th decades of life. Subsequent neuropathological studies have been discordant on the issue, perhaps not surprisingly when one considers the difficulties inherent in charting loss of components in so complex and crowded an area as the cortex, without specific markers. Air-encephalographic indications of atrophy ${ }^{3}$ were subject to the charge that patients were specially selected for the procedure.

Fresh impetus has come from computed tomographic (CT) scan studies, which uniformly reveal a high incidence of cortical shrinkage and ventricular dilatation in large and relatively unselected populations of alcoholics. ${ }^{4,5}$ Psychometry has revealed, even after thorough 'drying out', widespread cognitive deficits affecting memory, psychomotor speed, visuospatial and abstracting abilities and complex reasoning. ${ }^{6} \mathrm{CT}$ evidence suggests that about half to two thirds of alcoholics develop atrophy, often from quite early on in their alcoholic careers. ${ }^{5}$ A proportion of severe alcoholics escape entirely for reasons which remain unclear but include genetic factors, age and sex.

Genetic factors are indicated by more severe CT

Correspondence: R.R. Jacobson M.A., M.R.C.P., M.R.C. Psych.

Received: 6 November 1986 scan changes in familial than non-familial alcoholics. ${ }^{7}$ Age has repeatedly been shown to correlate with most indices of CT change, but it is difficult to separate the effects of age from those of the duration of alcoholism. The equivalence of CT abnormalities in older alcoholics with short and long drinking histories suggests that with advancing age the brain becomes more vulnerable to de novo exposure to alcohol. ${ }^{5,8}$ The rate of cerebral atrophy with aging eventually plateaus out in male alcoholics as indicated by CT $\operatorname{scan}^{9}$ and autopsy studies. ${ }^{10}$ Female alcoholics may be at greater risk, as they reveal equivalent ventricular enlargement and widening of the cortical fissures, but not sulci, after a shorter drinking history and at a lower peak alcohol consumption than male alcoholics. ${ }^{9}$ This accords with the female susceptibility to psychological deficits ${ }^{10}$ and to alcoholic liver disease. ${ }^{11,12}$

The abnormal changes resolve slowly with prolonged abstinence. ${ }^{5,13}$ The rate of recovery of brain shrinkage is too gradual for it to be explained by restoration to normal of water and electrolyte changes. Regeneration of dendritic spines ${ }^{14}$ occurs and changes in glial and neuronal proteins ${ }^{15}$ persist with abstinence. Does prolonged abstinence ultimately lead to total restitution of normal brain morphology? Cross-sectional studies comparing alcoholics with Alcoholics Anonymous (AA) members, who report prolonged abstention after equally severe drinking histories, reveal some degree of persistent ventricular dilatation in AA males, though with more complete restitution in AA females. ${ }^{9}$ The cortical sulci appear to have recovered completely in both sexes. X-ray absorption densities of frontal white matter are elevated in abstinent alcoholics compared to controls. ${ }^{16}$ This could be related to the altered lipid content of white matter reported by Lesch et al. ${ }^{17}$

Recent autopsy studies are beginning to confirm the validity of the CT scan findings. Brain weights were found to be significantly reduced in large numbers of male alcoholics compared to controls with a mean difference of $31^{18}$ or 71 grams. ${ }^{19}$ A quantitative estimate of the pericerebral space has been developed by Harper et al. ${ }^{19}$ from measures of the intracranial 
and brain volumes. This index of brain shrinkage was $70 \%$ greater in 22 chronic alcoholics than controls. A selective reduction was found in the volume of cerebral white rather than cortical gray matter. This may reflect a primary alteration in white matter composition or a secondary effect of cortical neuronal loss. The pericerebral space was greater in alcoholics with Wernicke's encephalopathy (WE) and maximal in those with alcoholic liver disease.

Wernicke's encephalopathy is less rare than previously supposed, even in a non-alcoholic context where it has accounted for $1 \%$ of a general medical firm's intake in Wales. ${ }^{20}$ In WE, the lesions are predominantly situated around the third ventricle affecting the diencephalon and brain $\mathrm{stem}^{21}$. The autopsy prevalence exceeds five-fold the clinical diagnostic prevalence during life. ${ }^{22}$ This discrepancy may relate to the rarity of the classical clinical triad and to 'missed' clinical signs, but the magnitude of the difference suggests that at least some cases of the Wernicke-Korsakoff syndrome (WKS) may be the end result of repeated subclinical episodes of thiamine deficiency ${ }^{23}$. This hypothesis has been supported directly by studies of rhesus monkeys subjected to intermittent thiamine deficiency ${ }^{24}$ and indirectly by one CT scan study showing an inverse association between memory performance and third, but not lateral, ventricular size in male non-Korsakoff alcoholics. ${ }^{25}$ Hence a high index of clinical suspicion must be maintained in the alcoholic for this potentially treatable complication of alcoholism, and preventive measures should be considered.

Wernicke's encephalopathy is due to thiamine deficiency. There may be a hereditary susceptibility related to genetic polymorphism for the transketolase enzyme ${ }^{26}$ but this is disputed. ${ }^{27}$ Only in alcoholics is WE followed by a permanent Korsakoff's syndrome. ${ }^{28}$ Therefore features associated with alcoholism, such as cortical shrinkage, could contribute to it. Cortical atrophy was noted in the WKS in $32 \%$ of autopsy cases by Harper \& $\mathrm{Kril}^{29}$ who considered that thiamine deficiency was the main factor. CT scan studies also reveal greater cortical and ventricular indices in Korsakoffs than age- and sex-matched alcoholics. However, except for third ventricular widths, these changes are accounted for by drinking history differences.

\section{References}

1. Lishman, W.A. Cerebral disorder in alcoholism. Syndromes of impairment. Brain 1981, 104: 1-20.

2. Courville, C.B. Effects of alcohol on the nervous system of man. San Lucas Press, Los Angeles, 1955.

3. Brewer, C. \& Perrett, L. Brain damage due to alcohol consumption: an air-encephalographic, psychometric
The relation between alcoholic liver disease and brain atrophy is not clearly established. In Harper \& Kril's ${ }^{29}$ study the pericerebral space was greater in alcoholics with than those without liver disease. Acker et al. ${ }^{30}$ found that cirrhotics had larger ventricles than normals, an effect accounted for by age differences, but cortical atrophy increased with the severity of liver pathology, independently of age. Already it is known that neuropsychological deficits occur in cirrhotics whatever the cause, and correlate significantly with certain liver enzyme and function indices. ${ }^{31} \mathrm{CT}$ studies comparing alcoholic and non-alcoholic cirrhotics are required.

The concept of a primary 'alcoholic dementia' separate from the WKS is controversial. The detection of such a condition relies on cross-sectional surveys, since longitudinal studies present insuperable problems. Alcoholism is thought to be the cause of otherwise unexplained dementia in about $8 \%$ of patients. ${ }^{\prime}$ Many patients labelled Korsakoff show evidence of global deficits and are indistinguishable from those with alcoholic dementia. ${ }^{32}$ Precise clinical and psychometric criteria are required to distinguish between a selective amnesic (Korsakoff) syndrome and the global deficits of dementia. The quantitative pathological changes in alcoholics described by Harper and colleagues do not exonerate complicatione such as head injury, anorexia, hypoglycaemia an niacin and vitamin $\mathbf{B}_{12}$ deficiencies. Moreover, in one large autopsy series, all cases of 'alcoholic dementia revealed WE. ${ }^{18}$ Despite evidence of the direct neurotoxicity of alcohol in animals ${ }^{33}$ the validity of the entity 'alcoholic dementia' remains unsettled. The issue requires nosological clarification and further quantitative analyses.

A compromised brain is likely to be especially vulnerable to the plethora of insults which complicate alcoholism and perhaps also to the natural processes of aging. These factors require much greater study to elicit their respective and interacting roles in the genesis of brain atrophy and dysfunction. Meanwhile we may intervene decisively in two ways to remedy the cerebral affection of alcoholics; first, to strive to ensure abstinence which is known to allow brain shrinkage to recede; and secondly, to be ready with parenteral vitamin supplements to halt the progress of an ingravescent Wernicke pathology.

and electro-encephalographic study. $\mathrm{Br} J$ Addict 1971, 66: $170-182$.

4. Wilkinson, D.A. Examination of alcoholics by computed tomographic (CT) scans: a critical review. Alcohol: Clin Exp Res 1982, 6, 31-45.

5. Ron, M.A. The alcoholic brain: C.T. scan and psy- 
chological findings. Psychol Med 1983, Monograph Supplement 3.

6. Acker, W. Objective psychological changes in alcoholics after the withdrawal of alcohol. Br Med Bull 1982, 38: 95-98.

7. Begleiter, H.J., Porjesz, B. \& Kissin, B. Brain dysfunction in alcoholics with and without a family history of alcoholism. Alcohol Clin Experimental Res 1982, 6, 136.

8. Jacobson, R.R. Female alcoholics: a controlled CT brain scan and clinical study. Br J Addict 1986, 81, 743-752.

9. Jacobson, R.R. The contributions of sex and drinking history to the CT brain scan changes in alcoholics. Psychol Med 1986, 16: 547-559.

10. Acker, C. Neuropsychological deficits in alcoholics: the relative contribution of gender and drinking history. $\mathrm{Br} \mathrm{J}$ Addict 1986, 81: 395-403.

11. Saunders, J.B., Davis, M. \& Williams, R. Do women develop alcoholic liver disease more readily than men? British Medical Journal 1981, 282, 1140-1143.

12. Gavaler, J.S. (1982). Sex-related difference in ethanolinduced liver disease: artificial or real? Alcoholism: Clinical and Experimental Research 1982, 6, 186-196.

13. Carlen, P.L., Wortzman, G., Holgate, R.C., Wilkinson, D.A. \& Rankin, J.G. Reversible cerebral atrophy in recently abstinent chronic alcoholics measured by computed tomographic scans. Science 1978, 200: 1076-1078.

14. West, J.R., Lind, M.D., Demuth, R.M. et al. Lesioninduced sprouting in the rat dentate gyrus is inhibited by repeated ethanol administration. Science 1982, 218, 808810.

15. Rosengren, L.E., Wronski, A., Briving, C. \& Haglid, K.G. Long lasting changes in gerbil brain after chronic ethanol exposure: a quantitative study of the glial cell marker S-100 and DNA. Alcoholism: Clinical and Experimental Research 1985, 9, 109-113.

16. Lishman, W.A., Jacobson, R.R. \& Acker, C. Brain damage in alcoholism: current concepts. Acta Med Scand 1986 (in press).

17. Lesch, P., Schmidt, E. \& Schmidt, F.W. Effects of chronic alcohol abuse on the structural lipids in the human brain. J Clin Chem Clin Biochem 1979, 10: 410415.

18. Torvik, A., Lindboe, C.F. \& Rogde, S. Brain lesions in alcoholics. A neuropathological study with clinical correlations. J Neurol Sci 1982, 56, 233-248.

19. Harper, C.G. \& Kril, J.J. \& Holloway, R.L. Brain shrinkage in chronic alcoholics: a pathological study. $\mathrm{Br}$ Med J 1985, 290: 501-504.

20. Anderson, S.H., Charles, T.J. \& Nicol, A.D. Thiamine deficiency at a district general hospital: report of five cases. $Q J$ Med 1985, 216: 15-32.

21. Victor, M., Adams, R.D. \& Collins, G.H. In The Wernicke-Korsakoff Syndrome. Blackwell, Oxford, 1971.

22. Harper, C.G., Giles, M.\& Finlay-Jones, R. Clinical signs in the Wernicke Korsakoff complex: a retrospective analysis of 131 cases diagnosed at necropsy. Neurol Neurosurg Psychiatry 1986, 49: 341-345.

23. Harper, C. The incidence of Wernicke's encephalopathy in Australia - a neuropathological study of 131 cases. $J$ Neurol Neurosurg Psychiatry 1983, 46: 593-598.

24. Witt, E.D. \& Goldman-Rakic, P.S. Intermittent thiamine deficiency in the rhesus monkey 1 . Progression of neurological signs and neuroanatomical lesions. Annals of Neurology 1983, 13, 376-395.

25. Acker, C., Jacobson, R.R. \& Lishman, W.A. Memory and ventricular size in alcoholics. Psychol Med 1987 (in press).

26. Blass, J.P. \& Gibson, G.E. Abnormality of a thiamine requiring enzyme in patients with Wernicke-Korsakoff syndrome. N Engl J Med 1977, 297: 1367-1370.

27. Pratt, O.E., Jeyasingham, M., Shaw, G.K. \& Thomson, A.D. Transketolase variant enzymes and brain damage. Alcohol Alcohol 1985, 20: 223-232.

28. Freund, G. Chronic central nervous system toxicity of alcohol. Ann Rev Pharmacol 1973, 13, 217-227.

29. Harper, C. \& Kril, J. Brain atrophy in chronic alcoholic patients - a quantitative pathological study. J Neurol Neurosurg Psychiatry 1985, 48: 211-217.

30. Acker, W., Aps, E.J., Majumdar, S.K., Shaw, G.K. \& Thomson, A.D. The relationship between brain and liver damage in chronic alcoholic patients. $J$ Neurol Neurosurg Psychiatry 1982, 45: 985-987.

31. Tarter, R.E. \& Edwards, K.L. Multifactorial etiology of neuropsychological impairment in alcoholics. Alcohol Clin Exp Res 1986, 10, 128-135.

32. Cutting, J. The relationship between Korsakoff's syndrome and "alcoholic dementia". Br J Psychiatry 1978, 132: $240-251$.

33. Riley, J.N. \& Walker, D.W. Morphological alterations in hippocampus after long-term alcohol consumption in mice. Science 1978, 201: 646-648. 